\title{
MICROSTRUCTURAL EVOLUTION AND MECHANICAL PROPERTIES OF RHEOCAST Al-7.1WT\%Si ALLOY
}

\author{
Mehdi Raeissia $^{I^{*}}$ and Behzad Niroumand ${ }^{2}$ \\ ${ }^{1}$ Department of Materials Engineering, Faculty of Engineering, \\ Shahrekord University, Shahrekord, 88186-34141,Iran \\ ${ }^{2}$ Department of Materials Engineering, Isfahan University of Technology, \\ Isfahan, 84156-83111, Iran
}

Received 18.03.2016

Accepted 26.08.2016

\begin{abstract}
Effects of Semi-Solid Rheocasting (SSR) process on the structure and mechanical properties of $\mathrm{Al}-7.1 \mathrm{wt} \% \mathrm{Si}$ alloy were studied. The results showed that the non-dendritic structure could be formed by a short stirring period below liquidus temperature provided that stirring was combined with localized rapid heat extraction from the melt. The effect was examined by calculation of the time needed for detachment of dendrite arms at the initial stages of solidification and was associated with a large particle density in the rheocast slurry. Samples processed in semisolid state had lower porosity, higher tensile strength and higher elongation than that processed in fully-liquid state. The SSR- processed sample had a lower tensile strength but a higher elongation than the sample cooled without localized cooling and stirring. It was suggested that the lower strength of SSR-processed alloy was related to the inability of the $\alpha$-particles to restrain crack propagation through the brittle eutectic matrix.

Keywords: Semisolid rheocasting, particle density, Dendrite arm detachment, Ripening model, Tensile strength.
\end{abstract}

\section{Introduction}

Researches on rheology of semisolid slurries suggest that the ideal slurry for semisolid metal (SSM) processing is one containing a suitable volume fraction of fine and spheroidal particles uniformly dispersed in a low melting liquid matrix [1]. The processes invented for generating such non-dendritic microstructures can be classified into two routes according to their mechanism of microstructure evolution [2], namely dendrite fragmentation and nucleation mechanisms. In the first type of processes, the liquid metal is cooled to its semisolid temperature to form primary dendrites which are subsequently fragmented, mainly by use of some sort of stirring, into small particles suitable for semi-solid processing. The stirring methods include mechanical stirring,

\footnotetext{
${ }^{*}$ Corresponding author: Mehdi Raeissia, raeissi@eng.sku.ac.ir
} 
electromagnetic stirring, gas bubbling, electric shock agitation, etc [1, 2]. In the second type of processes, formation of dendritic particles at the start of solidification is prevented by controlling the cooling conditions of the liquid. These processes are more time and cost efficient than those based on the dendrite fragmentation mechanism.

Several rheocasting processes based on the nucleation mechanism have been developed in recent years, some of which are being commercialized in the casting industry. These include, for example, include the NRC (New RheoCasting) [3], the SEED (Swirled Enthalpy Equilibration Device) [4], Low superheat pouring with a shear field (LSPSF) [5], Gas induced semi-solid (GISS) [6], Cooling slope [7] SSR (SemiSolid Rheocasting) [8] and RSF (Rapid Slurry Forming) [9] processes.

The SSR process is fundamentally different from other rheocasting processes in the view that the molten alloy is converted to semisolid slurry by applying instantaneous rapid cooling and convection for a very short time during the early stages of solidification [8]. In this process, molten alloy is held a few degrees above its liquidus temperature. Solidification starts with the insertion of a rotating cold rod into the melt. The rotating rod is removed after a short interval and the quiescent melt is further cooled to the casting temperature and poured into a die [8]. It has been shown that desirable non-dendritic microstructures can be formed quickly and efficiently just by a short processing of the molten alloy at its liquidus temperature [8, 10-12].

This paper reports parts of the results of an investigation on the effects of SSR process on the structure and mechanical properties of rheocast $\mathrm{Al}-7.1 \mathrm{wt} \% \mathrm{Si}$ alloy and compares them with those of conventionally cast samples. Also attempt is made to explain the microstructural changes brought about by the SSR process based on its effect on the density of the primary particles formed during the early stages of solidification.

\section{Experimental procedures}

Fig.1(a) shows the rheocasting set-up employed in carrying out the experiments which was comprised of a resistance furnace, a graphite crucible having bottom pouring arrangements and a graphite stirring rod. Casting conditions used in different experiments are presented in Table 1 and explained below.

\section{Comparison of SSR-processed and conventionally-solidified samples}

For the conventionally-solidified sample (No. 1), the alloy was melted and held for 3 minutes at a temperature $10^{\circ} \mathrm{C}$ above its measured liquidus temperature and was then allowed to cool down inside the furnace to room temperature The cooing rate of the melt when passing the liquidus temperature $\left(\mathrm{T}_{1} \pm 1^{\circ} \mathrm{C}\right)$ and within the entire semisolid zone was about 0.07 and $0.04{ }^{\circ} \mathrm{Cs}^{-1}$, respectively.

For the SSR-processed sample (No. 2), the melt was prepared similarly. However, the cold graphite rod rotating at $1000 \mathrm{rpm}$ was immersed into the melt at $3{ }^{\circ} \mathrm{C}$ superheat removing the superheat almost instantly. The rod was kept in the melt for about 7 seconds cooling the melt to a temperature corresponding to 0.05 fraction solid. The rod was then removed and the alloy was allowed to cool down inside the furnace to room temperature. The cooing rate of the melt when passing the liquidus temperature $\left(\mathrm{T}_{1} \pm 1{ }^{\circ} \mathrm{C}\right)$ and within the entire semisolid zone was about 0.13 and $0.04{ }^{\circ} \mathrm{Cs}^{-1}$, respectively. 

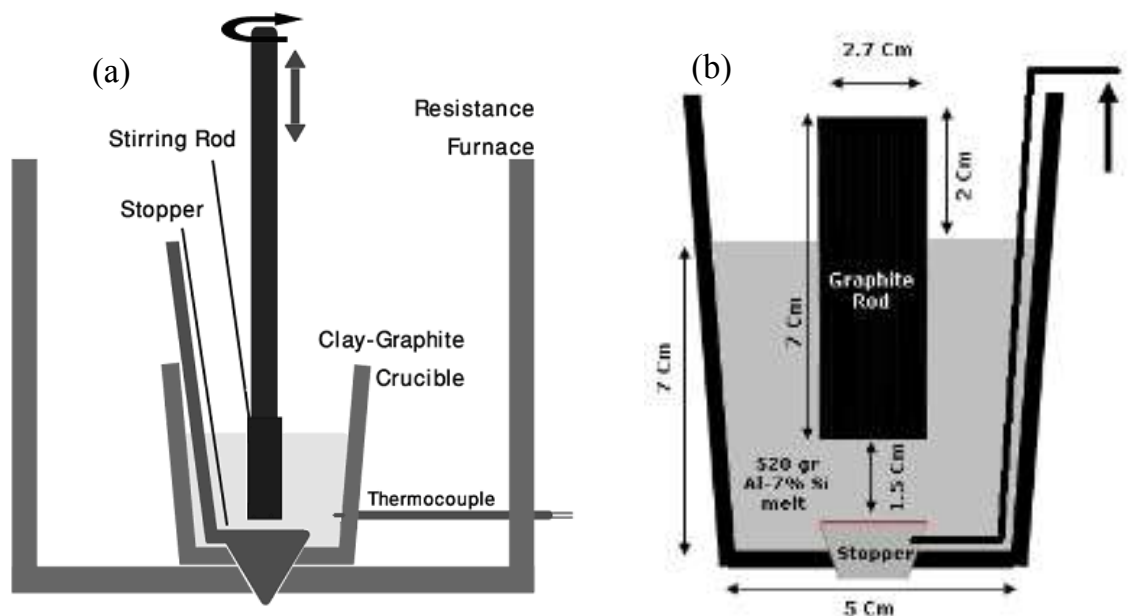

Fig.1. (a) Schematic of the equipment designed and built for this study and (b) The position of stirring rod in the crucible.

Effects of SSR process on porosity content and mechanical properties of the alloy

In order to evaluate the effects of SSR process on the porosity content and mechanical properties of the alloy, three samples were produced under different conditions. Sample No. 3 was cast from fully liquid state into a steel die. For sample No. 4 , the melt was cooled down in the furnace to 0.3 solid fraction without stirring and cast in the steel die.

Table 1. Casting conditions used in different experiments.

Comparison between the SSR-processed and the conventionally-solidified alloy

\begin{tabular}{|l|l|l|l|l|l|}
\hline Sample & $\begin{array}{l}\text { weight } \\
(\mathbf{g r})\end{array}$ & $\begin{array}{l}\text { Cooling rate at } \\
\mathbf{T}_{\mathbf{1}} \pm \mathbf{1}^{\mathbf{}} \mathbf{C}\left({ }^{\circ} \mathbf{C s}^{-1}\right)\end{array}$ & $\begin{array}{l}\text { Solidification } \\
\text { time (min) }\end{array}$ & $\begin{array}{l}\text { Stirring } \\
\text { time (sec) }\end{array}$ & $\begin{array}{l}\text { Stirring speed } \\
(\mathbf{r p m})\end{array}$ \\
\hline 1 & 520 & 0.07 & 20 & - & - \\
\hline 2 & 520 & 0.13 & 20 & 7 & 1000 \\
\hline Comparison between various casting processes \\
\hline Sample & $\begin{array}{l}\text { weight } \\
\text { (gr) }\end{array}$ & $\begin{array}{l}\mathbf{C o o l i n g ~ r a t e ~ a t ~} \\
\mathbf{T}_{\mathbf{1}} \pm \mathbf{1}^{\circ} \mathbf{C}\left({ }^{\circ} \mathbf{C s}^{-1}\right)\end{array}$ & $\begin{array}{l}\text { Stirring time } \\
(\mathbf{s e c})\end{array}$ & $\begin{array}{l}\text { Stirring } \\
\text { speed (rpm) }\end{array}$ & $\begin{array}{l}\text { Casting } \\
\text { condition }\end{array}$ \\
\hline 3 & 520 & - & - & - & liquid state \\
\hline 4 & 520 & 0.07 & - & - & 0.3 solid \\
\hline 5 & 520 & 0.13 & 7 & 1000 & 0.3 solid \\
\hline
\end{tabular}

In the third experiment (sample No. 5), the alloy was heated and held in the furnace at approximately $3^{\circ} \mathrm{C}$ superheat. The graphite rod rotating at $1000 \mathrm{rpm}$ was then immersed into the melt. The rod was kept in the melt for about 7 seconds (correspond to 0.05 solid fraction), after which it was removed and the slurry was allowed to cool slowly in the furnace without stirring to 0.3 solid fraction and cast in the steel die.

Characterisation methods 
Microstructural investigations were carried out on polished and etched samples cut from the castings. Porosity contents of the castings were measured using equation (1):

$$
\% \text { Porosity }=\left(1-\frac{\rho_{\text {app }}}{\rho}\right) \times 100
$$

where the apparent density, $\rho_{\text {app }}$, of each sample was obtained by Archimedes method and the actual density of $\mathrm{Al}-7.1 \mathrm{wt} \% \mathrm{Si}$ alloy, $\rho$, was extracted from literature $[13,14]$.

Tensile tests were carried out on specimens made according to Fig.2 [15] using a Hounsfield tensile machine (H50KS model) under a strain rate of $0.01 \mathrm{~min}^{-1}$.

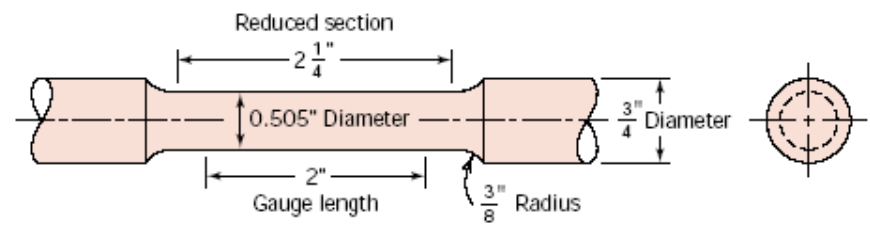

Fig.2. The tension test specimen according to ASTM E8.

\section{Results and discussion}

Comparison of SSR-processed and conventionally solidified samples

Fig.3(a) shows the microstructure of the conventionally cast alloy with large dendrites and widely spaced secondary arms. The dendrites are surrounded by eutectic constituents which appear darker in the micrograph. Fig.3(b) shows the SSR-processed microstructure consisting of large spheroidal particles surrounded by the eutectic constituents located at particles boundaries.

The comparison of these two microstructures indicates the higher density of the nucleated and grown $\alpha$-particles in the SSR-processed microstructure. In another words, the figures suggest that the formation of non-dendritic structures in rheocast alloys can be the result of a significantly greater particle density than that of the dendritic structure in conventional solidification.

In the SSR-processed alloy, immersion of the cold rod induces a region of high local cooling rate in the melt and considerably increases the nucleation intensity of the primary particles on or in the areas adjacent to the rod surface. Rotation of the rod causes a through distribution of the solid particles formed in the melt. Furthermore, the generated melt convection makes the temperature distribution in the melt relatively uniform increasing the possibility of the nuclei survival. These conditions can lead to an increased particles density in the microstructure of the SSR-processed alloy.

Study of the mechanism of microstructure formation in the SSR processed alloy requires an understanding of the effects of such region of high local cooling rate on the primary particles density. Therefore an attempt is made to study the effects of such region on the average time for melting off of the dendrite arms and to relate it to the primary particles density. For this purpose, first the heat-transfer coefficient of the $\mathrm{rod} / \mathrm{melt}$ interface and the average particles size must be estimated. 


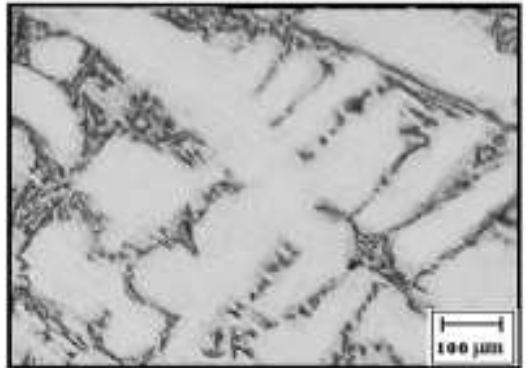

(a)

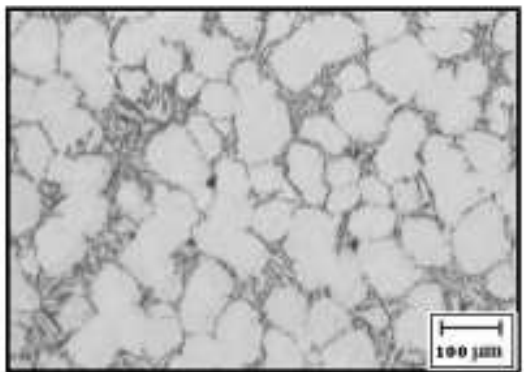

(b)

Fig.3. (a) Conventionally solidified structure and (b) SSR-processed structure of Al-7.1wt\%Si alloy (Both samples cooled inside the furnace until the end of the solidification)

Ignoring the heat loss from the melt surface and from the crucible walls compared with that through the graphite stirring rod, it can be assumed that the heat flow out of the melt, $\mathrm{Q}_{\text {out }}^{\circ}$, equals the heat flow into the stirring rod, $\mathrm{Q}^{\circ}$ in. The rate of heat flow out of the melt during stirring time of $\Delta t$ is approximated by equation (2);

$$
\mathrm{Q}_{\mathrm{out}}^{\circ} \approx \frac{\mathrm{Mf}_{\mathrm{s}} \Delta \mathrm{H}}{\Delta \mathrm{t}}
$$

where $M$, fs and $\Delta H$ are the mass of the melt, the solid fraction formed during stirring and the heat of fusion per unit mass of pure aluminum, respectively. The heat flow into the graphite stirring rod can be approximated by equation (3) [16];

$$
\mathrm{Q}_{\mathrm{in}}^{\circ} \approx \mathrm{Ah}_{\mathrm{rod}}\left(\Delta \mathrm{T}_{\mathrm{r}}\right)
$$

where $\mathrm{A}, \mathrm{h}_{\mathrm{rod}}$ and $\Delta \mathrm{T}_{\mathrm{r}}$ are the total rod-melt contact area, the heat-transfer coefficient of the rod/melt interface and the temperature difference between the rod and the melt, respectively. Equating equations (2) and (3) yields:

$$
\mathrm{h}_{\mathrm{rod}} \approx \frac{(\mathrm{M}) \mathrm{f}_{\mathrm{s}} \Delta \mathrm{H}}{\mathrm{A} \Delta \mathrm{T}_{\mathrm{r}}(\Delta \mathrm{t})}
$$

The dendrite arm spacing (DAS) of the dendrites which form on or near the rod surface can be estimated using the following approach adapted from Ref. [17].

It is assumed that the heat flow into the cooling rod is interface controlled; the mother dendrites are growing radially on the rod surface and in the opposite direction to the heat flow and the full volumetric heat of fusion of aluminum is removed by the cooling rod for each increment of growth of the dendrite tip. Under these conditions the average dendrites tip velocity, $\mathrm{R}_{\mathrm{s}}$, can be taken as an estimate of the solidification rate and may be expressed as;

$$
\mathrm{R}_{\mathrm{s}}=\frac{\mathrm{h}_{\mathrm{rod}} \Delta \mathrm{T}_{\mathrm{r}}}{\rho \Delta \mathrm{H}}
$$


By substituting $\mathrm{h}_{\mathrm{rod}}$ from equation (4) in equation (5), the final expression for estimating the average dendrites tip velocity is obtained;

$$
\mathrm{R}_{\mathrm{s}}=\frac{(\mathrm{M}) \mathrm{f}_{\mathrm{s}}}{\rho \mathrm{A}(\Delta \mathrm{t})}
$$

Substituting fs equal to 0.05 (the solid fraction of sample No. 2 after 7 seconds of stirring) and A equal to $48 \mathrm{~cm}^{2}$ (using the geometry and the immersion depth of the rod which shown in Fig.1(b)) into equation (6), the average dendrites tip velocity of sample No. 2 is estimated to be slightly greater than $0.3 \mathrm{~mm} / \mathrm{s}$.

Equation (7) shows the relationship between the dendrite tip radius and the dendrites tip velocity [16];

$$
\mathrm{r} \approx 2 \pi\left(\frac{\mathrm{D}_{1} \Gamma}{\left(\Delta \mathrm{T}_{0}\right) \mathrm{K} \mathrm{R}}\right)^{1 / 2}
$$

where $r$ is the dendrite tip radius, $D_{1}$ is the solute diffusivity in the melt, $\Gamma$ is Gibbs- Thompson coefficient, $\Delta \mathrm{T}_{0}$ is the solidification range for the alloy and $\mathrm{K}$ is the solute partition ratio. Fig. 4 depicts the relationship for $\mathrm{Al}-7.1 \mathrm{wt} \% \mathrm{Si}$ using the parametric values extracted from Ref. [13]. Fig.4 shows that at dendrite tip velocity of $0.3 \mathrm{~mm} / \mathrm{s}$ the corresponding tip radius would be approximately $1.5 \mu \mathrm{m}$.

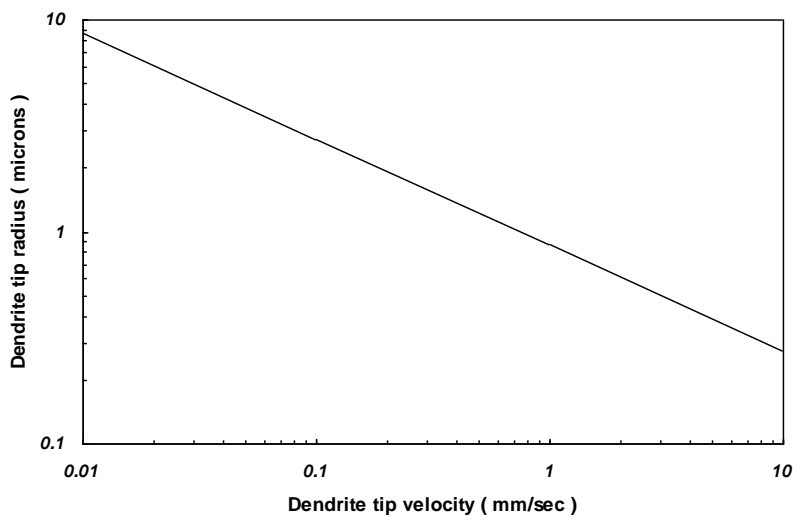

Fig.4. Relationship between dendrite tip radius and dendrite tip velocity for Al-7.1wt $\% \mathrm{Si}$

On the other hand, the time required for a dendrite arm to be detached from its mother dendrite by melting off of its root due to ripening, $t_{\text {crit }}$, can be calculated using equation (8) proposed by Kattamis et al. [18];

$$
\mathrm{t}_{\text {crit }}=0.0085 \frac{\rho \Delta \mathrm{H} \mathrm{C}_{0} \mathrm{~m}_{1}(1-\mathrm{K}) \mathrm{d}^{3}}{\sigma \mathrm{D}_{1} \mathrm{~T}}
$$


where $\sigma$ is the solid-liquid interfacial energy, $d$ is DAS, $\mathrm{C}_{0}$ is solute content of the alloy and $\mathrm{ml}$ is slope of the liquidus line. Assuming the dendrite arm spacing to be about twice the tip radius ( $3 \mu \mathrm{m}$ for sample No. 2$)$ and that the temperature (T) is just below the liquidus temperature (corresponding to 0.05 solid fraction after 7 seconds of stirring), the critical time for detachment of the arms is worked out to be approximately 0.1 second.

For sample No. 1 which was solidified inside the furnace without insertion of the rotating graphite rod, DAS after 7 seconds of solidification is estimated to be $15 \mu \mathrm{m}$ using the empirical ripening equation of the alloy (equation (9)) [11]:

$$
\mathrm{DAS}=8.73(\Delta \mathrm{t})^{1 / 3}
$$

By substituting this value into equation (8), the critical time for arms detachment is approximated to be about 12.5 seconds. These approximations clearly show the significant influence of the insertion of the cold graphite rod into the melt on the number of free moving solid particles during solidification.

Furthermore, in the presence of a high local cooling zone, when the dendrites start to grow with an initial tip radius of approximately $1.5 \mu \mathrm{m}$, stirring accelerates the arm melt off and grain multiplication through the thermal and mechanical influences on the dendrite and carries the detached arms into the bulk of the melt. At the same time, the stirring action of the cooling rod is likely to make the temperature gradient in the melt relatively uniform and eliminates any regions of high local temperature in the bulk of the melt resulting in continuous growth of a large density of the separated particles. As a result the particles spacing becomes very small and the particles will have limited space for growth.

On the other hand, in such circumstances, the probability of overlap of the diffusion fields of the adjacent particles increases significantly which leads to the decrease of the concentration gradients in front of the solid-liquid interfaces and removes the driving force for the instability of the growing interfaces. Under these conditions, the particles will have limited but more stable growth and the non-dendritic structure is expected to form in a short period after the start of solidification. Conversely, if the local chilling is not complemented by stirring, solidification of the dendrites would progress with less arm detachment while ripening of the initial dendrite arms proceeds. It is expected that natural convection can carry away only a portion of the detached particles into the bulk of the melt. Even then many of the carried away particles may face regions of high local temperature and re-melt. Thus the relatively small number of the survived particles will have large inter-particle spacing and therefore most of the particles growing away from the cooling rod find enough chances for equiaxed dendritic growth. The final structure would be columnar or equiaxed dendritic.

A third scenario can also be envisioned when the density of the separated particles is intermediate between the two aforementioned conditions. This situation may arise when the stirring is not strong enough. In this condition, the distances between the primary particles are still large but diffusion fields overlap may take place at later stages of solidification. Therefore primary particles will have more chance and space to start and continue part of their growth with unstable interfaces. They will ripen into rosettes 
and later into spheroids under the effects of stirring and diffusion fields overlap. In such conditions longer stirring times are required for formation of the non-dendritic structure.

Thus, it is postulated that the required time for formation of non-dendrite particles after the start of solidification is inversely related to the initial density of the particles formed just below the liquidus temperature. The higher the particles density, the shorter the time needed for the formation of non-dendritic microstructure. Fig.5 depicts the typical microstructures for samples No. 3 to 5 processed at three different conditions.

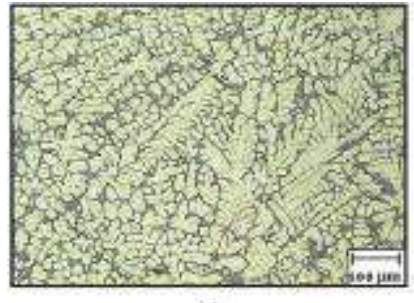

(3)

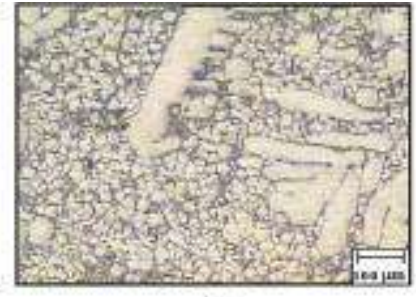

(b)

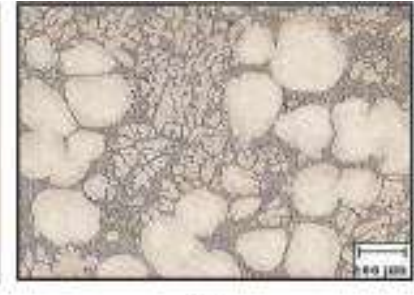

Fig.5. Typical microstructures of the (a) alloy processed in fully-liquid state, (b) alloy processed in semisolid state without stirring and (c) SSR-processed alloy.

For sample No. 3 cast from fully liquid state (Fig.5(a)), the $\alpha$-phases have dendritic morphology. Sample No. 4 which was cooled to 0.3 solid fraction before casting (Fig.5(b)) contains large primary dendrites with an average DAS of $37 \mu \mathrm{m}$. The remaining melt solidified in the die (secondary particles) has also dendritic morphology with an average DAS of less than $10 \mu \mathrm{m}$. In the SSR-processed sample (No. 5), the morphology of the primary particles solidified before casting is non-dendritic while that of the secondary particles is dendritic (Fig.5(c)).

Effects of SSR process on porosity content and mechanical properties of the alloy

The porosity content and mechanical properties of samples No. 3 to 5 are shown in Table 2. The comparison between the porosity contents of these samples indicates that the sample cast from the fully liquid state has higher porosity content than those of the samples processed in semisolid state. Considering the fact that in samples No. 4 and 5 , which have been cast from the semisolid state, part of the solidification and its associated shrinkage has taken place outside the die, the result seems reasonable.

Table 2. Porosity contents and mechanical properties of samples No. 3, 4 and 5.

\begin{tabular}{|l|l|l|l|}
\hline Sample No. & Volume Porosity $(\%)$ & Tensile Strength (MPa) & Elongation (\%) \\
\hline 3 & $5.48 \pm 0.11$ & $127 \pm 7$ & $9.14 \pm 0.11$ \\
\hline 4 & $4.61 \pm 0.07$ & $161 \pm 5$ & $9.8 \pm 0.15$ \\
\hline 5 & $4.36 \pm 0.08$ & $150 \pm 4$ & $9.97 \pm 0.1$ \\
\hline
\end{tabular}

Although the casting temperatures were the same for the two semisolid-cast samples, the porosity content of the SSR-processed sample was relatively lower. Viscosity of solidifying melts has been shown to rise gradually with increasing the solid fraction until reaching the dendrite coherency point (DCP) [19] after which it increases abruptly. At DCP a continuous 3D solid skeleton is formed in the casting which makes 
the feeding difficult. This marks the transition from liquid and mass feeding to interdendritic feeding during solidification [20]. In semisolid non-dendritic slurries, the DCP is reached at higher solid fractions due to the change in the morphology and the size of the primary particles. Thus it is believed that the lower porosity content of the SSR-processed alloy is due to the more extended and effective operation of liquid and mass feeding mechanisms toward the end of solidification.

A comparison between the strengths of samples No. 3 to 5 shows that the sample cast from fully liquid state has the lowest tensile strength. The high porosity of this sample is believed to have reduced its tensile strength.

The major constituents present in hypoeutectic A1-Si alloys are the aluminumrich $\alpha$ - solid solution and the eutectic structure. Semisolid processing of these alloys permits dispersion of ductile particles of proeutectic $\alpha$-phase in a matrix of brittle eutectic [21].

Such a structure allows them to be considered as brittle matrix ductile dispersoid particulate composites. For the brittle matrix-ductile particle composites it has been proposed that the role of ductile particles is to restrain the crack propagation through the brittle matrix. The mechanism by which such a restraint is affected is believed to be the compressive stresses which the ligaments of the unbroken particles joining the crack faces exert to restrain the displacement of the crack faces. It has been suggested that for the above mechanism to be operative, particles of cylindrical morphology should be used instead of spheroidal particles. When spheroidal particles are employed, the crack in the matrix simply by-passes the particles and no crack particle interaction results [22]. It appears, therefore, that the lower strength of SSR-processed alloy containing spheroidal particles in comparison with the sample processed in semisolid state without stirring is related to the inability of spheroidal $\alpha$-particles to restrain crack propagation through the brittle eutectic matrix.

The comparison between the elongations of the samples (Table 2) indicates that elongations of the samples are inversely related to the porosity content of the samples.

\section{Conclusions}

1- Non-dendritic structure can be formed by a short stirring period below liquidus temperature provided that stirring is combined with rapid heat extraction from the melt. This treatment produces significantly larger particle density in the rheocast alloys which result in the formation of non-dendritic structures.

2- The sample cast from fully-liquid state had a higher porosity content and lower tensile strength and elongation in comparison with those processed in semisolid state. The longer operation of liquid and mass feeding mechanisms seems to be a contributor to lower porosity of the SSR-processed sample compared to the sample cast at the same solid fraction without SSR treatment.

3- The results indicated that the SSR-processed sample had a lower tensile strength than the sample cast at the same solid fraction without SSR treatment. It was suggested that the lower strength of SSR-processed alloy was related to the inability of the spheroidal $\alpha$ - particles to restrain crack propagation through the brittle eutectic matrix.

\section{References}

[1] M.C. Flemings: Metal. Trans., 1991, 22A, 957-981. 
[2] Z. Fan: Int. Mater. Rev. 47 (2002) 49-85.

[3] H. Kaufmann, P.J. Uggowitzer, Adv. Eng. Mater. 3 (2001) 963-967.

[4] S. Nafisi, R. Ghomashchi, Mater. Sci. Eng. 415A (2006) 273-285.

[5] H.M. Guo, X.J. Yang, J.X. Wang, Mater. Sci. Forum 628 (2009) 477-482.

[6] R. Canyook, J. Wannasin, S. Wisuthmethangkul, M.C. Flemings, Acta Mater. 60 (2012) 3501-3510.

[7] E.C. Legoretta, H.V. Atkinson, H. Jones, J. Mater. Sci. 43 (2008) 5448-5455.

[8] R.A. Martinez, A. Karma, M.C. Flemings: Metal. Mater. Trans. 37A (2006) $2807-$ 2815.

[9] M. Payandeh, Anders E.W. Jarfors, M. Wessén, Metal. Mater. Trans. 47A (2016) 1215-1228.

[10] M. Reisi, B. Niroumand: J. Alloys Compd. 475 (2009) 643-647.

[11] M. Reisi, B. Niroumand: J. Alloys Compd 470 (2009) 413-419.

[12] M. Reisi, B. Niroumand, , J. Mater. Chem. Phys. 135 (2012) 738-748.

[13] Ch. -A. Gandin: Acta Mater. 48 (2000) 2483-2501.

[14] G. Heiberg, Ch. -A. Gandin, H. Goerner, L. Arnburg: Metall. Mater. Trans. 35A (2004) 2981-2991.

[15] ASTM E8/E8M-08 Standard Test Methods for Tension Testing of Metallic Materials.

[16] R.B. Bird, W.E. Stewart, E.N. Lightfoot: 'Transport Phenomena' $2^{\text {nd }}$ edn, Wiley, New York, 2002.

[17] W. Kurz, D.J. Fisher: 'Fundamentals of Solidification', $4^{\text {th }}$ edn, Trans. Tech. Publication, Switzerland, 1998.

[18] T.Z. Kattamis, U.T. Holmberg, M.C. Flemings: J. Inst. Met. 95 (1967) 343-347.

[19] D.B. Spencer, R. Mehrabian, M.C. Flemings: Met. Trans. 3 (1972) 1925-1932.

[20] A.K. Dahle, D.H. Stjohn: Acta Mater. 47 (1999) 31-41.

[21] A. Vogel, R.D. Doherty, B.C. Cantor: Proc. Conf. on 'Solidification and Casting of Metals', Metals Society, Sheffield, UK, 1977, p. 518.

[22] A.G. Evans, A.H. Heuer, D.L. Porter: Proc. $4^{\text {th }}$ Int. Conf. on Fracture, Waterloo, 1977, University of Waterloo Press, p.529. 